\title{
Thesis conducted by student in medical informatics field based on health informatics competencies framework: A study in Iran
}

\author{
Elham Nazari ${ }^{(1)}$, Mehran Aghemiri² (i), Seyed Mohammad Tabatabaei ${ }^{1}$ (D), Sayyed Mostafa

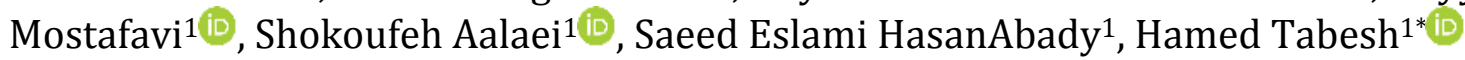

1Department of Medical Informatics, Faculty of Medicine, Mashhad University of Medical Sciences, Mashhad, Iran

${ }^{2}$ Department of Medical Informatics, Faculty of Medical Sciences, Tarbiat Moddares University, Tehran, Iran

\begin{tabular}{|c|c|}
\hline Article Info & A B S T R A C T \\
\hline $\begin{array}{l}\text { Article type: } \\
\text { Research }\end{array}$ & \multirow{3}{*}{$\begin{array}{l}\text { Introduction: One of the challenges of multidisciplinary disciplines such as } \\
\text { Medical Informatics, is the lack of familiarity with research fields. Due to the } \\
\text { specializations and clinical facilities concentrated in each university, } \\
\text { research is being done differently and with variety. Therefore, in this study, } \\
\text { in order to identify the most researched fields and the neglected fields of } \\
\text { research, the dissertations done in the field of medical informatics in Iranian } \\
\text { universities were studied based on the health informatics framework. } \\
\text { Material and Methods: Defended dissertations available to master and } \\
\text { doctoral students of medical informatics during } 2011 \text { to } 2019 \text { in the } \\
\text { universities of Tehran, Iran, Tarbiat Modares, Shahid Beheshti, Shiraz, } \\
\text { Tabriz and Mashhad were collected. Three medical informatics experts } \\
\text { assigned dissertation titles to a competency and an area of skill based on } \\
\text { health informatics competencies framework. The second stage of the study } \\
\text { was performed by two other experts (different from the previous three } \\
\text { experts). Each dissertation title was assigned to a specific competency and a } \\
\text { specific area of skill by the majority opinion method. }\end{array}$} \\
\hline $\begin{array}{l}\text { Article History: } \\
\text { Received: } 2020-07-25 \\
\text { Accepted: } 2020-08-23 \\
\text { Published: } 2020-09-02\end{array}$ & \\
\hline $\begin{array}{l}\text { Department of Medical Informatics, } \\
\text { Faculty of Medicine, Mashhad } \\
\text { University of Medical Sciences, } \\
\text { Mashhad, Iran }\end{array}$ & \\
\hline $\begin{array}{l}\text { Keywords: } \\
\text { Medical Informatics } \\
\text { Software Engineering } \\
\text { Healthcare } \\
\text { Framework } \\
\text { Dimensions }\end{array}$ & $\begin{array}{l}\text { Results: The results showed that the most of master and doctoral } \\
\text { dissertations were in the field of information science and methods, in which } \\
\text { area of skill of data analysis and visualization, which decision support } \\
\text { systems and informatics for participatory health were more than others. } \\
\text { Among PhD students, the area of skill of decision support system and } \\
\text { architecture of health information systems were more popular. PhD } \\
\text { students at the universities of Mashhad, Tehran and Shahid Beheshti worked } \\
\text { in the field of methods and basic principles of activities more than other } \\
\text { areas, information and communication technology, biomedical science and } \\
\text { health were not considered. }\end{array}$ \\
\hline & $\begin{array}{l}\text { Conclusion: Results of this research could be helpful for field researchers in } \\
\text { terms of conducting new research in the field and can help to design useful, } \\
\text { scientific and effective research projects. }\end{array}$ \\
\hline
\end{tabular}

Cite this paper as:

Nazari E, Aghemiri M, Tabatabaei SM, Mostafavi SM, Aalaei S, Eslami HasanAbady S, Tabesh H. Thesis Conducted by Student in Medical Informatics Field Based on Health Informatics Competencies Framework: A Study in Iran. Front Health Inform. 2020; 9: 42. DOI: 10.30699/fhi.v9i1.230

\section{INTRODUCTION}

One of the challenges of multidisciplinary disciplines such as medical informatics, health information management, health information technology, etc., especially for beginners and people who have started research in this field, is the lack of familiarity with the research fields of these fields. Medical Informatics is an interdisciplinary field in which computer science, software, information science, medicine, statistics, mathematics and cognitive sciences can be used. The task and mission of this field is to use concepts, tools, methods and software techniques and modeling to improve health care services, reduce costs and care errors [1- $\underline{4}]$.

This field is a new field in Iran and has been accepting students for masters and doctoral degrees in different universities for 11 years. Due to the interdisciplinary nature of medical informatics, 
research fields can cover a wide range of fields, and on the other hand, due to the special facilities and specialties of each university, research fields will be limited. The purpose of the field is to conduct research and provide services at all levels of care, including prevention, diagnosis, treatment and management levels, so familiarity with research fields in this field is very important. Because it helps researchers in choosing an important, appropriate and useful research field, and as a result, the gaps and challenges in the field of health care will be identified and addressed, and great and valuable services will be provided to the field of health care. Therefore, in the present study, in order to identify the most researched fields in this field and the neglected fields of research, the dissertations done in the field of medical informatics in Iranian universities were reviewed based on the health informatics framework.

The health informatics competencies framework, edition 1.0, provided by Australia, was used as a reference and classification model to categorize research conducted in Iran by medical informatics students. The framework is used to diagnose health informatics skills and knowledge, and the defined theses in medical informatics were matched in many countries, including Canada, the United States, Australia, and Germany. In knowledge and skill in this framework is presented in the form of 7 dimensions of competency and each competency has a number of area of skill [ $\underline{5}]$.

The competencies mentioned in this framework are:

1-information and communication technology

2-health and biomedical science

3-information science

4-management science

5-core principles and methods

6-human and social context

7-specializations

Competencies 1 to 7 have 5, 10, 8, 5, 20, 4 and 8 area of skill, respectively.

\section{MATERIAL AND METHODS}

In this study, the dissertations of master's and doctoral students in medical informatics in Iranian universities between 2011 and 2019 were reviewed. In Iran, the universities of Tehran, Shahid Beheshti, Iran, Mashhad and Kerman accept students in both master's and doctoral degrees, and Tarbiat Modares, Shiraz, Urmia, Tabriz and Ahvaz universities have students only in the master's degree. In the present study, 261 dissertation titles were collected based on the inclusion and exclusion criteria that will be stated below. The thesis was collected in three ways: 1- By referring to the university website. 2- Visiting universities in person and citing the manuscripts available in the library. 3- By students studying in this field. The health informatics competencies framework was considered as a standard framework related to the field of medical informatics in order to categorize the research fields of the dissertations. Three medical informatics graduate from different universities assigned the titles of the dissertations to the appropriate competencies and the area of skills based on the framework. The opinion of each medical informatics specialist was reviewed separately and independently and the assignment was done based on the majority of opinions. In the next step, to reexamine the disagreements in some dissertations, the opinions of two other experts (different from the previous three experts) were used. After this stage, a general agreement was reached on the dissertation rent and all dissertations were assigned to the related competencies and area of skills.

\section{Inclusion criteria and exit criteria:}

Inclusion criteria:

1. The desired field of study is medical informatics

2. Degree studied for masters and doctoral degrees

3. Defended dissertations in Iranian universities in this field between 2011 and 2019

Exclusion criteria:

1. Defended proposals

2. Ongoing dissertations

3. The thesis is not available

\section{RESULTS}

In this study, the dissertations of Tehran, Shahid Beheshti, Iran, Mashhad, Tarbiat Modares, Shiraz and Tabriz universities were included in the study according to the inclusion criteria and Kerman university due to lack of access to dissertations through the site and impossibility of face-to-face referral due to The incidence of COVID-19 disease and poor student cooperation were excluded. Also, the universities of Urmia and Ahvaz stated that they did not have a defended dissertation on the desired date.

The frequency of dissertations in the field of medical informatics in different competencies and universities of Iran can be seen in the Table 1.

As can be seen in Table 1, the most competitions where dissertations were done in the country were competency 5 and 3, and in competencies 2, 4 and 6 the number of dissertations was very low. The same pattern is seen in each university. In Iran, Tehran and 
Mashhad universities, the frequency of dissertations was higher in competency 5 and in other universities in competency 3 .

As can be seen in Fig 1, in most universities, research activities in the field of methods and basic principles have been in competition with information science. In the doctoral program, the University of Mashhad, Tehran and Shahid Beheshti have done more activities in the field of methods and basic principles than other fields.

According to the results of Fig 2, 3 and 4, area of skill of data analysis and visualization, decision support systems and informatics for participatory health were the most considered by doctoral students.
As can be seen from Fig 5, the year of 2014 was the year for most postgraduate research in Tehran and Shahid Beheshti Universities. Also, most of the research in the doctoral program in 2017 was related to Mashhad, which can be related to the capacity of universities in that year.

As can be seen from Fig 6, most of the research in the master's degree program has been related to Competency called information science. Also, most of the research in the doctoral program in 2017 was related to Competency called core principles and methods.

Table 1: Frequency of dissertations in the field of medical informatics in various competencies and universities in Iran

\begin{tabular}{|c|c|c|c|c|c|c|c|c|}
\hline $\begin{array}{c}\text { Competency/ } \\
\text { University } \\
\text { name }\end{array}$ & 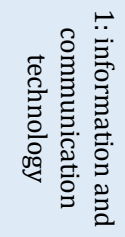 & 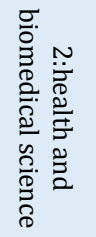 & 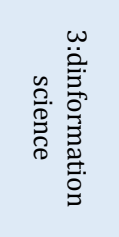 & 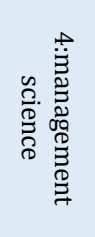 & 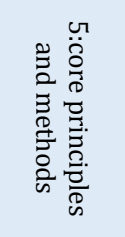 & 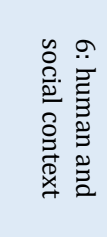 & 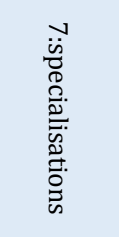 & Total \\
\hline & $\mathrm{n}(\%)$ & $\mathrm{n}(\%)$ & $\mathrm{n}(\%)$ & $\mathrm{n}(\%)$ & $\mathrm{n}(\%)$ & $\mathrm{n}(\%)$ & $\mathrm{n}(\%)$ & $\mathrm{n}(\%)$ \\
\hline Iran & $1(7.7)$ & $1(50)$ & $12(12.5)$ & $0(0)$ & $15(11.4)$ & $0(0)$ & $3(27.3)$ & $32(12.3)$ \\
\hline Mashhad & $3(23.1)$ & $0(0)$ & $18(18.8)$ & $0(0)$ & $38(28.8)$ & $1(16.7)$ & $0(0)$ & $60(23)$ \\
\hline $\begin{array}{l}\text { Shahid } \\
\text { Beheshti }\end{array}$ & $1(7.7)$ & $0(0)$ & $30(31.3)$ & $0(0)$ & $28(21.2)$ & 1(16.7) & $1(9.1)$ & $61(23.4)$ \\
\hline Shiraz & $3(23.1)$ & $0(0)$ & $11(11.5)$ & $1(100)$ & $7(5.3)$ & $2(33.3)$ & $2(18.2)$ & $26(10)$ \\
\hline Tabriz & $0(0)$ & $0(0)$ & $2(2.1)$ & $0(0)$ & $1(0.8)$ & $0(0)$ & $0(0)$ & $3(1.1)$ \\
\hline $\begin{array}{l}\text { Tarbiat } \\
\text { Moddares }\end{array}$ & $2(15.4)$ & $1(50)$ & $11(11.5)$ & $0(0)$ & $10(7.6)$ & $1(16.7)$ & $2(18.2)$ & $27(10.3)$ \\
\hline Tehran & $3(23.1)$ & $0(0)$ & $12(12.5)$ & $0(0)$ & $33(25)$ & $1(16.7)$ & $3(27.3)$ & $52(19.9)$ \\
\hline Total & $13(100)$ & $2(100)$ & $96(100)$ & $1(100)$ & $132(100)$ & $6(100)$ & $11(100)$ & $261(100)$ \\
\hline
\end{tabular}
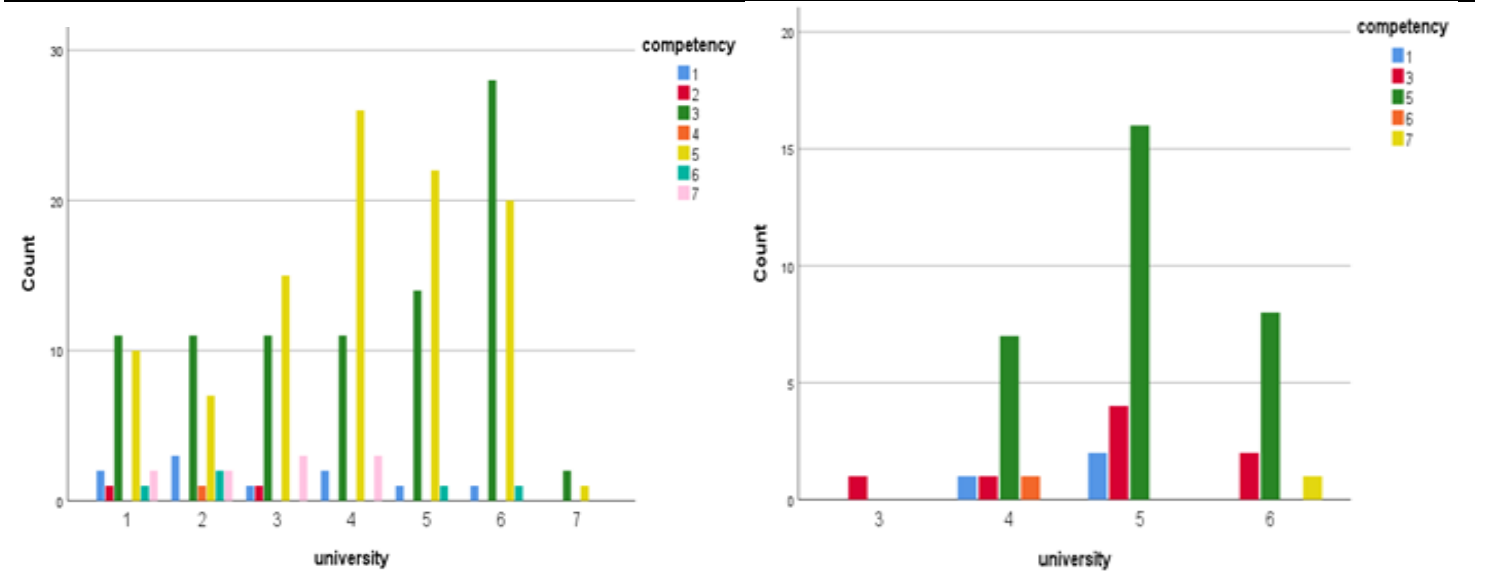

Competency: 1-Information and communication technology 2-Health and biomedical science 3-Information science 4-Management science 5- Core principles and methods 6-Human and social context 7-Specialisations

University: 1-Tarbiat Modares University 2-Shiraz University of Medical Sciences 3-Iran University of Medical Sciences 4- Tehran University of Medical Sciences 5- Mashhad University of Medical Sciences 5- Shahid Beheshti University of Medical Sciences 6- Tabriz University of Medical Sciences

Fig 1: Frequency of defended medical informatics dissertations in each competency in (a) master and (b) PhD degree in Iran 


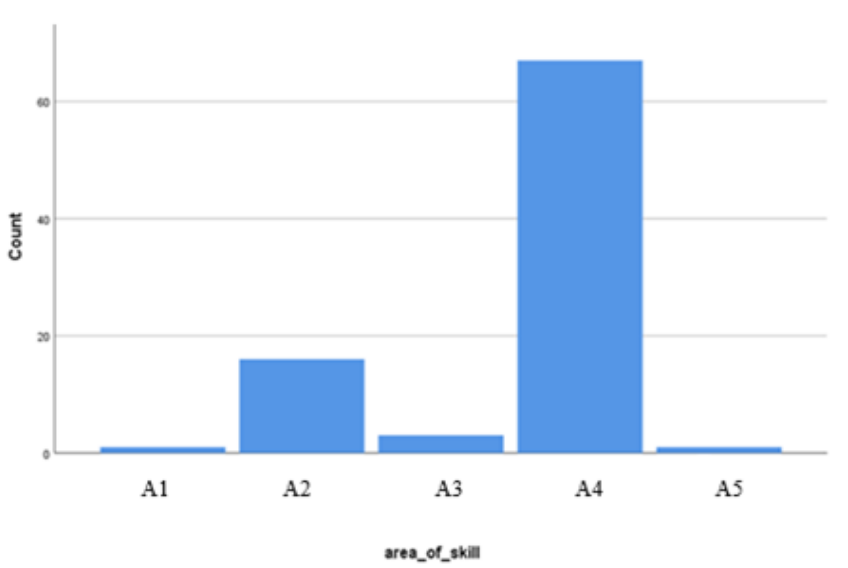

A1: Applicable mathematical concepts; A2: Realisation of benefits from IS; A3: Attributes \& limitations of data \& information; A4: Data analysis and visualization; A5: Identification of gaps in data sources

Fig 2: Frequency of medical informatics PhD dissertations in competency called information science in terms of area of skill

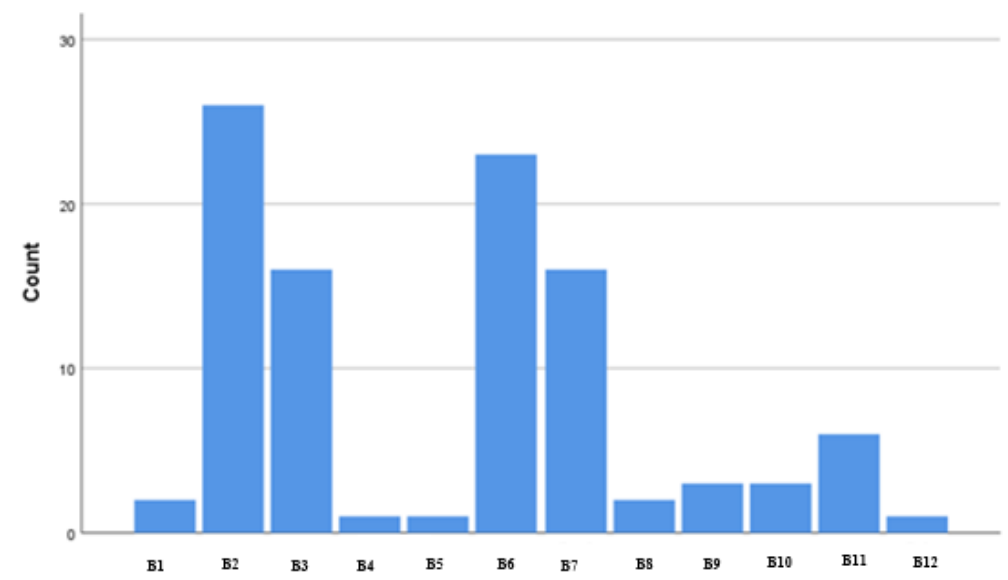

B1: History of health and biomedical informatics (HBI) \& analysis of related literature; B2: Decision support systems; B3: Architectures of Health IS; B4: Interoperability \& HI standards; B5 Clinical safety \& IS; B6: Informatics for participatory health; B7: E-health applications and solutions; B8: Conceptual frameworks in HBI; B9: IS to support patients; B10: Electronic health record; B11: Informatics in support of education \& research; B12: Interfacing \& patient identification.

Fig 3: Frequency of medical informatics doctoral dissertations in competency called core principles and methods in terms of area of skill

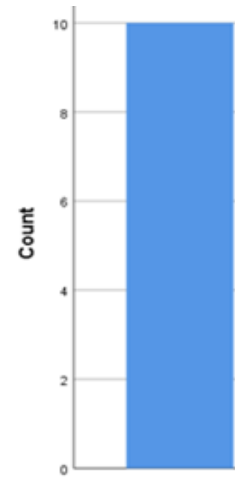

c1

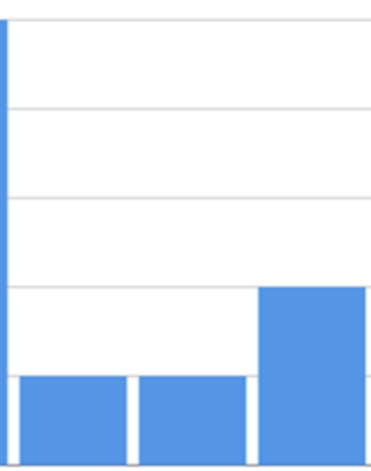

C3

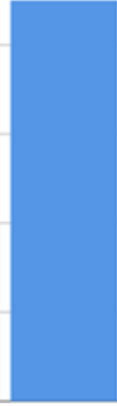

c5

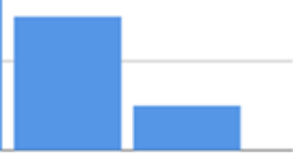

c6

C7

area_of_skill

C1: Decision support systems; C2: Architectures of Health IS; C3: Clinical safety \& IS; C4: Informatics for participatory health; C5: E-health applications and solutions; C6: IS to support patients

Fig 4: Frequency of medical master thesis in competency called core principles and methods 

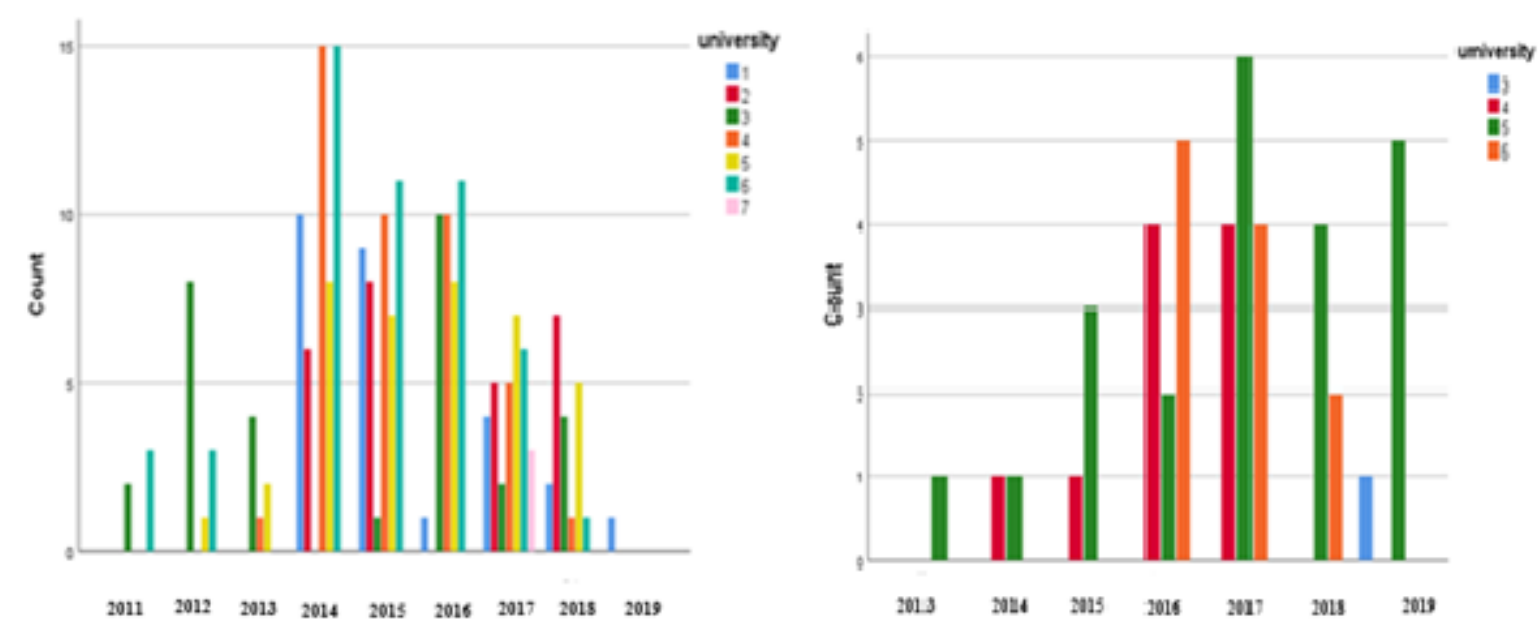

a) Master thesis (left) b) PhD thesis (right)

1: Tarbiat Modares University; 2: Shiraz University; 3: Iran University; 4: Tehran University; 5: Mashhad University; 6: Shahid Beheshti University; 7: Tabriz University;

Fig 5: Frequency of defended dissertations in master's and doctoral degrees in Medical Informatics in different universities from 2011-2019
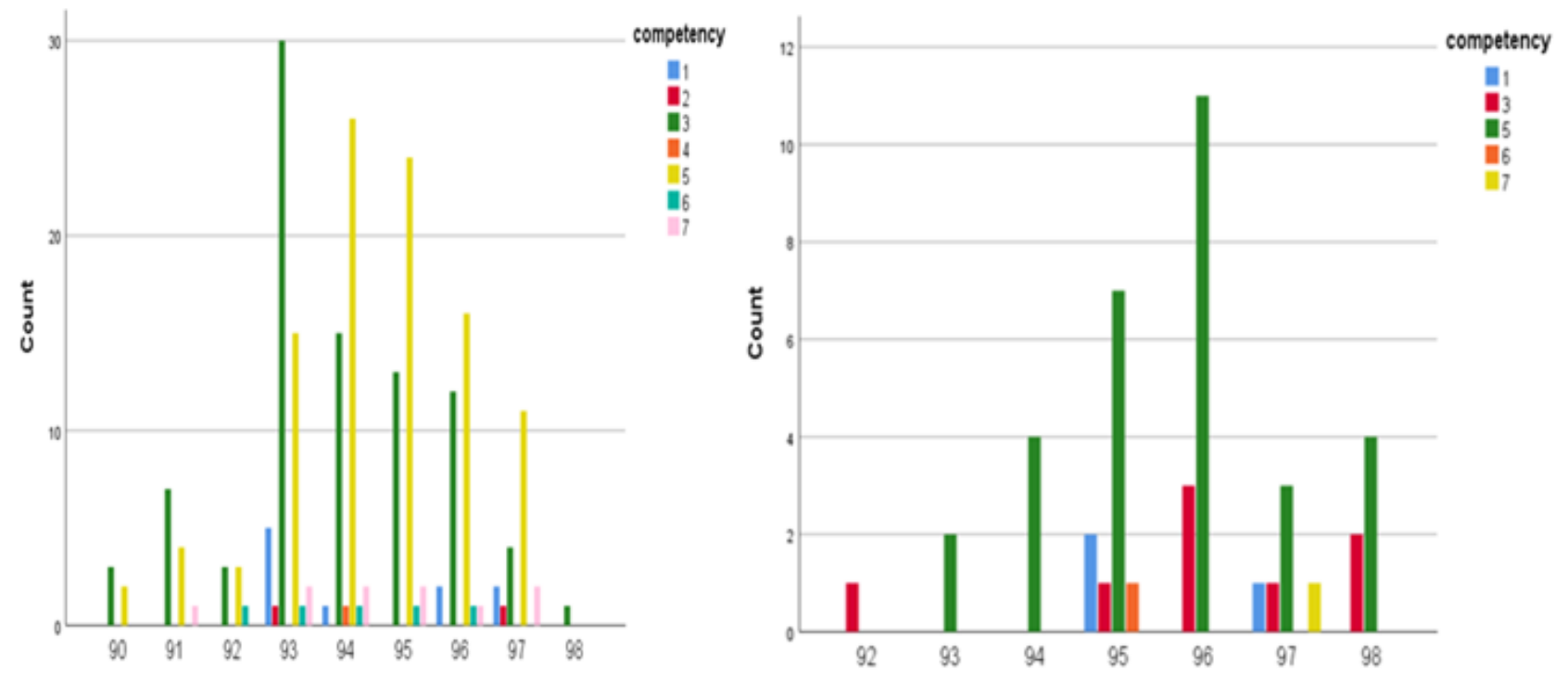

a) Master thesis (left) b) PhD thesis (right)

1: Information and communication technology; 2: Health and biomedical science; 3: Information science; 4: Management science; 5: Core principles and methods; 6: Human and social context; 7: Specialisations

Fig 6: Frequency of defended dissertations in masters and doctoral degrees in medical informatics in terms of competitions

\section{DISCUSSION}

One of the challenges of interdisciplinary fields such as Medical Informatics, especially for students who have started research in other fields, is the lack of familiarity with research fields in this field. Therefore, in the present study, the categories of dissertations worked in Iranian universities in the field of medical informatics in master's and doctoral degrees based on the Health Informatics Competencies Framework were distributed to determine the research fields of students in this field in Iran and that Identify the ones that have not been addressed.
The results of the study showed that most of the theses worked in this field in most Iranian universities based on the health informatics competencies framework were related to competitions with the titles of Core principles and methods and Information science. Not much research has been done on management science and human and social context. In the doctoral program, the universities of Mashhad, Tehran and Shahid Beheshti have performed more activities in these two competitions than in other fields. It should be noted that the universities of Tehran, Shahid Beheshti, Iran, Mashhad and Kerman have doctoral students and the admission capacity of different universities should not be neglected because the frequency of research 
conducted in some universities can be related to the number of students admitted.

It seems that the focus of each university on specific topics depends on the facilities available in the universities in the field, including access to clinical centers and professors in different specialties and costs. In different universities, because the university may not have much connection with clinical and hospital centers, on the other hand, university professors have different specializations in engineering and basic sciences, medical records, management, etc. Most of the theses defined in these universities in These two have been Competency and have been directed to these two general directions and not much research has been done in other fields. For example, the specialty of most professors at Tarbiat Modares University is engineering and basic sciences, and most of the professors at the University of Tehran specialize in medical records and health information management.

The tendency towards these two competencies can also be interpreted in such a way that perhaps the need for health care centers and clinical centers in Iran has been more in these two directions, therefore, more research has been done in these two fields.

According to the findings, most of the dissertations submitted in 2014 were related to the master's degree and in the universities of Tehran and Shahid Beheshti, and the most dissertations submitted in the doctoral program in 2017 were related to the University of Mashhad, which can be the reason for this is due to the long master's or doctoral course and the concurrence of dissertation presentations of different years due to the choice of different topics by students or due to the high admission capacity of students in some universities, more research has been done. Due to the interdisciplinary nature of medical informatics, the use of professors in different fields and specialties in Iranian universities can be effective in defining topics for research for theses. This study is the first study conducted for this purpose in Iran and the world, and a similar study sample was not found for comparison based on our knowledge. The only sources found in the searches were the titles of dissertations in this field and on the websites of various universities, including Australia. , The United States, Canada and Germany have been observed. In the general review of dissertation titles done in these countries, it was concluded that the scope of dissertations is based on the competencies and area of skills of the Health Informatics
Competencies Framework. Therefore, this framework it was considered as a study model [으- $\underline{9}]$. It should not be forgotten that the field of informatics in different countries is older than Iran and Iran can benefit from the experiences of those countries in order to enrich the field. It is suggested that future studies of other universities and new dissertation titles submitted in the years after 2018 be considered. It is also recommended that this study be conducted in different universities in different countries to enable the comparison of research areas in this field in different countries.

\section{CONCLUSION}

Iran is a country in which the field of medical informatics is a fledgling field and few universities, including the universities of Tehran, Shahid Beheshti, Iran, Tarbiat Modares, Mashhad, Shiraz, Kerman, Tabriz, Urmia and Ahvaz accept students in this field. Research at each university is different and varied, but some important areas related to the field may be overlooked. The results of this study can help field researchers in conducting new research in the field and can help in the design of useful, scientific and effective research projects of researchers, university professors and educational planners and health care service providers to define research in Seven competency health informatics frameworks can take effective steps to improve the quality of care services and reduce errors.

The field of medical informatics has various research fields related to the use of technology in the field of health care with the aim of reducing costs and improving the quality of health care and can provide valuable services.

\section{AUTHOR'S CONTRIBUTION}

The authors agree on this final form of the manuscript, and attested that all authors contributed in the final draft of the manuscript.

\section{CONFLICTS OF INTEREST}

The authors declare no conflicts of interest regarding the publication of this study.

\section{FINANCIAL DISCLOSURE}

No financial interests related to the material of this manuscript have been declared.

\section{REFERENCES}

1. Wyatt JC, Liu JL. Basic concepts in medical informatics. J Epidemiol Community Health. 2002; 56(11): 808-12. PMID: 12388565 DOI: $10.1136 /$ jech.56.11.808 [PubMed]
2. Shortliffe EH, Cimino JJ. Biomedical informatics: Computer applications in health care and biomedicine. London: Springer; 2006.

3. Musen MA, van Bemmel JH. Handbook of medical informatics. Houten, the Netherlands: Bohn Stafleu 
Van Loghum; 1997.

4. Schrenker RA. Software engineering for future healthcare and clinical systems. Computer. 2006; 39(4): 26-32.

5. Competencies framework [Internet]. 2016 [cited: 1 Jun 2020]. Available from: https://www.healthinformaticscertification.com/wp -content/uploads/2016/02/CHIA-competenciesFramework_FINAL.pdf

6. Study in Canada [Internet]. 2019 [cited: 12 Jun 2020]. Available from: https://www.mastersportal.com/studyoptions/269353243/health-informatics-canada.html

7. Master of science in clinical and health informatics [Internet]. 2018 [cited: 1 Jul 2020]. Available from: https://pdc.wisc.edu/welcome-clinical-health- informatics $/$ ?utm_source=google\&utm_medium=sea rch\&utm_campaign=aycchi_search\&utm_content=chi _vendi_google_search_general_expanded_text_3\&gcli $\mathrm{d}=$ CjwKCAjwvZv0BRA8EiwAD9T2VXqp0Y3vvthczW $\mathrm{V}$ -

ZrS9tA_Kdtk0jMlJrrrJWuPrJd7w4vIrMsbCVhoCuYsQ AvD_BwE

8. Study in Germany [Internet]. 2019 [cited: 12 Jun 2020]. Available from: https://www.mastersportal.com/studyoptions/268615963/health-informaticsgermany.html

9. Study in Australia [Internet]. 2019 [cited: 12 Jun 2020]. Available from: options/271745307/health-informaticsaustralia.html 